\title{
THE IMPACT OF COVID-19 PANDEMIC ON THE UTILIZATION OF PEDIATRIC DENTAL CARE OF EGYPTIAN CHILDREN: A RETROSPECTIVE STUDY
}

\author{
Randa Youssef Abd Al Gawad* and Rasha Mohamed Hatem Hanafy**
}

\begin{abstract}
Background: The novel Coronavirus pandemic may have a strong influence on the utilization of emergency pediatric dental services. Aim: To assess how the novel COVID-19 pandemic influenced emergency pediatric dental treatment utilization patterns in Egypt.

Methods: Data of children seeking urgent dental care for the first time for 20 consecutive working days before the declaration of the partial curfew in Egypt [Group (1)] and another 20 days after that date [Group (2)] were retrieved from the Electronic Archive Filing System Unit and statistically analyzed.

Results: The study included data of 705 children (Group (1): 470, Group (2): 235); where the number of children reduced to about half. There were non-significant differences between Group $(1 \& 2)$ regarding different types of emergency and non-emergency treatment requirements. Most of the children before (99.1\%) and after curfew (98.3\%) sought emergency treatment due to dental caries.

Conclusions: COVID-19 pandemic influenced the number of children seeking urgent dental services; however, the treatment requirements are nearly similar. The proportion of pediatric emergency and non-emergency dental complaints are comparable before and after the partial curfew.
\end{abstract}

KEYWORDS : COVID-19; Dental; Emergency; Pediatric; Utilization

\section{INTRODUCTION}

In January 2020, scientists isolated the novel coronavirus (SARS-CoV-2) as the causative agent of severe acute respiratory distress outbreaking in Wuhan, Hubei, China ${ }^{1}$ The virus was different from the previously mutated forms SARS-CoV, MERS$\mathrm{CoV}$, and avian influenza ${ }^{2,3}$. The WHO declared the disease as a Public Health Emergency of International Concern (PHEIC), and it was named COVID-19

\footnotetext{
* Associate Professor of Pediatric Dentistry and Dental Public Health, Faculty of Dentistry, Cairo University، Egypt.

** Lecturer of Pediatric Dentistry and Dental public health, Faculty of Dentistry, Cairo University, Egypt.
} 
Egypt took active public health measures to spread the knowledge about the pandemic and to increase the population awareness towards the specific infection control methods through mass media. However, the increasing count of infected cases forced the governmental authorities to adopt the policy of defeating the pandemic through partial curfew declared on the $15^{\text {th }}$ of March 2020, intensive surveillance, active treatment, and hospital isolation of confirmed cases, home isolation of suspected cases, trying, by all means, to cut off the known possible transmission routes ${ }^{5}$

The Egyptian health authorities ordered the medical and dental institutions, which are considered as a high zone of infection transmission, to suspend general treatment, and to provide only emergency services, and hotline telephone services were offered, as an alternative, to minimize direct contact ${ }^{5,6}$.

The utilization of health services is the core of health care operations, resulting from the interaction between the behavior of the users and the professionals who conduct them within this system. It is also related to access (the act of entering, entrance) and accessibility (quality of what is accessible) ${ }^{7}$

The government policy factors and personal considerations (objective fear) experienced by the normal population regarding the mortality rate announced daily by the WHO from different countries of the world, lack of current definitive curative treatment, and the flow of awareness information that the aerosol produced through dental procedures could be contaminated with the virus, and is a potential source of spread of infection to dentists and dental personnel make people reluctant to dental treatment and rely mainly on medications $\mathbf{s}^{7,8}$

The COVID-19 pandemic had a strong influence on the utilization of emergency dental services in Beijing, China. Fewer patients visited the dental urgency at the beginning of the pandemic than before. The distribution of dental problems has changed significantly. The proportion of dental and oral infections raised from $51 . \%$ of pre-COVID-19 to $71.9 \%$ during COVID-19 and dental trauma decreased from $14.2 \%$ to $10.5 \%$. Meanwhile, the non-urgency cases reduced to three-tenths of preCOVID-199

The influence of the pandemic on the utilization of pediatric dental care in Egypt is unpredictable due to lack of current information. Therefore, the current study was held to assess how the novel COVID-19 pandemic influenced emergency pediatric dental treatment utilization patterns offered by Cairo University.

\section{MATERIALS AND METHODS}

\section{Study settings:}

Archive Filing System Unit of the Pediatric Dentistry Out-Patients' Clinic, Department of Pediatric Dentistry and Dental Public Health, Faculty of Dentistry, Cairo University.

\section{Study design}

The current study is a retrospective cohort study.

\section{Sample size estimation}

A convenient sample was adopted; retrieving data of all children seeking dental diagnosis and treatment for the first time at the Out-Patients' Clinic of Pediatric Dentistry and Dental Public Health department for 20 consecutive working days before 15 of March 2020 (date of declaration of partial curfew in Egypt) and another 20 consecutive working days after 15 of March 2020.

\section{Participants}

\section{Eligibility criteria}

The data of children fulfilling the following criteria were included in the study:

\section{Inclusion Criteria:}

1. Children from birth up to 15 years old.

2. Both genders were included. 
3. Children attending the department for the first time seeking urgent dental treatment.

\section{Exclusion Criteria:}

Children attending the department for the followup visits.

\section{Procedures:}

The research protocol was approved by the Department Research Board. Ethical approval was obtained from the Committee of Ethics, Faculty of Dentistry, Cairo University under the reference code: 26620 .

All data of children, with complete diagnostic records, who attended the department for the first time seeking urgent dental care for 20 consecutive working days before the $15^{\text {th }}$ of March 2020 [Group (1)] and for another 20 consecutive working days after the $15^{\text {th }}$ of March 2020 [Group (2)] were retrieved from the Electronic Archive Filing System Unit and revised for consistency and confirmed by the Hard Copy Archive Filing System by the second investigator.

The Policy of the Faculty Out-Patients' Clinic services allows using filing data by the investigators in research work which is also announced to all patients on a wall panel. The confidentiality of all children data retrieved for this study was totally preserved by the investigation team.

The number of children visiting the Out-Patients' Clinic of the teaching hospital, their demographic data, reasons for visiting the clinic, and the treatment required in the first visit were recorded. Treatment required was classified into emergency dental care including dental caries, acute gingival conditions, and traumatic dental injuries, and non-emergency dental care including esthetic problems, restorative needs, and miscellaneous asymptomatic problems (remaining roots, loose teeth, eruption problems, tongue tie, etc.).

\section{Addressing potential sources of bias}

\section{a) Selection bias:}

There was no risk of selection bias as the study included all data of children fulfilling the eligibility criteria.

\section{b) Information bias:}

Information bias was avoided by including only the data of all children fulfilling the eligibility criteria and data were sent to the statistician as labeled data to avoid any bias.

\section{c) Reporting bias:}

Reporting bias was avoided by reporting all data assessed.

\section{Statistical analysis:}

-Categorical data were presented as frequencies (n) and percentages (\%). Intergroup comparisons were done utilizing Fisher's exact test, $(p \leq 0.05)$. Statistical analysis was performed with $\mathrm{R}$ statistical analysis software version 4.0.2 for Windows ( $R$ Foundation for Statistical Computing, Vienna, Austria).

\section{RESULTS}

The study included data of 705 children visiting the Out-Patients' Clinic for the first time seeking urgent dental care. Group (1) included data of 470 children and Group (2) included 235 children where the number of children seeking dental services was reduced to about half the number after Egypt declaration of partial curfew.

The demographic characteristics of participants were listed in Table (1). There were non-significant differences regarding gender distribution $(p=0.552)$. Cases studied after the curfew had a significantly higher mean age value $(7.61 \pm 2.33)$ than those before $(6.70 \pm 2.42)(\boldsymbol{p}<0.001)$. Also, there was a significant difference between the distribution of living places between both groups $(\boldsymbol{p}<0.001)$, with most of the 
TABLE (1): Summary statistics of demographic data of both groups

\begin{tabular}{|c|c|c|c|c|c|}
\hline \multicolumn{3}{|c|}{ Feature } & Group (1) & Group (2) & $p$-value \\
\hline \multirow{4}{*}{$\begin{array}{l}\dot{\bar{\theta}} \\
\overline{0} \\
\dot{0}\end{array}$} & Male & n & 253 & 120 & \multirow{4}{*}{$0.522 \mathrm{~ns}$} \\
\hline & $\begin{array}{c}(\mathrm{n}=\mathbf{3 7 3}) \\
\%\end{array}$ & $53.8 \%$ & $51.1 \%$ & & \\
\hline & \multirow{2}{*}{$\begin{array}{c}\text { Female } \\
(\mathrm{n}=332) \\
\%\end{array}$} & $\mathbf{n}$ & 217 & 115 & \\
\hline & & $46.2 \%$ & $48.9 \%$ & & \\
\hline \multicolumn{2}{|c|}{ Age } & $\begin{array}{c}\text { Mean } \\
\pm \text { SD }\end{array}$ & $6.70 \pm 2.42$ & $7.61 \pm 2.33$ & $<0.001 *$ \\
\hline \multirow{6}{*}{ 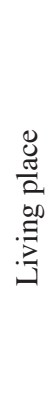 } & Cairo & n & 346 & 70 & \multirow{6}{*}{$<0.001 *$} \\
\hline & $\begin{array}{c}(\mathrm{n}=416) \\
\%\end{array}$ & $73.6 \%$ & $30.0 \%$ & & \\
\hline & Giza & $\mathbf{n}$ & 122 & 150 & \\
\hline & $\begin{array}{c}(\mathrm{n}=272) \\
\%\end{array}$ & $26.0 \%$ & $64.4 \%$ & & \\
\hline & \multirow{2}{*}{$\begin{array}{c}\text { Other } \\
(n=15) \\
\%\end{array}$} & $\mathbf{n}$ & 2 & 13 & \\
\hline & & $0.4 \%$ & $5.6 \%$ & & \\
\hline
\end{tabular}

*; significant $(p \leq 0.05)$ ns; non-significant ( $p>0.05)$

children investigated before curfew 346 (73.6\%) were living in Cairo, while 150 (64.4\%) children were living in Giza.

Frequency (n) and percentage (\%) values for emergency and non-emergency treatment before and after the date of declaration of partial curfew were illustrated in Table (2), Fig. (1). There were non- significant differences between Group ( 1 \& 2) regarding different types of emergency treatment (dental caries, acute gingival conditions, and traumatic injuries) and non-emergency treatment requirements (esthetic problems, restorative needs, and miscellaneous problems) where $p$ values were 0.549 and 0.715 respectively. Most of the children before $442(99.1 \%)$ and after curfew 174 (98.3\%) sought emergency treatment due to dental caries. Similarly, most of the children before 17 (70.8\%) and after curfew $46(78.0 \%)$ had non-emergency dental needs which were neither esthetic nor restorative.
TABLE (2): Frequency (n) and percentage (\%) values for emergency and non-emergency treatment of both groups.

\begin{tabular}{|c|c|c|c|c|c|}
\hline \multirow{2}{*}{ Treatment } & \multicolumn{2}{|c|}{ Complain } & $\begin{array}{c}\text { Group } \\
(1)\end{array}$ & $\begin{array}{c}\text { Group } \\
(2) \\
(\mathrm{n}=470)\end{array}$ & \multirow{2}{*}{ (n=235) }
\end{tabular}

*; significant ( $p \leq 0.05)$ ns; non-significant $(p>0.05)$

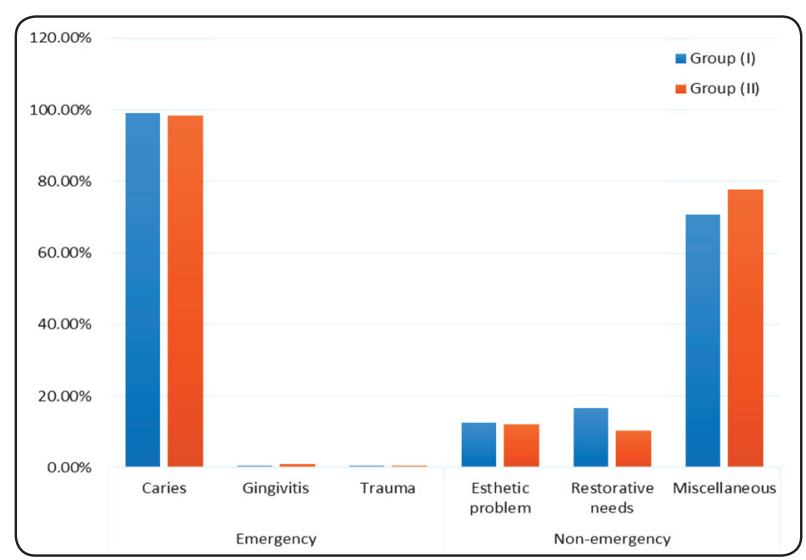

Fig. (1) Bar chart showing emergency and non-emergency treatment requirements of both groups. 


\section{DISCUSSION}

In response to the COVID-19 pandemic in March 2020, the Centers for Disease Control and Prevention (CDC) recommended that dental settings should be restricted to urgent and emergency services and elective dental treatment should be deferred to protect patients, dentists and dental personnel, and to preserve personal protective equipment and patient care supplies ${ }^{10}$

As part of the emergency guidance, the American Dental Association (ADA) declared on 18 March 2020 that dental procedures should only be restricted to the management of conditions that require immediate intervention (acute pain and/or risk of infection) to minimize the burden on hospital emergency units ${ }^{11}$

The current study is a retrospective cohort study of archive children's dental data in a special period and presents meaningful findings of emergency dental visits related to lifestyle lockdown related to the newly emergent pandemic.

The Pediatric Dentistry Out-Patients' clinic of the Faculty of Dentistry, Cairo University is considered the main refuge offering dental services to a wide range of children. Nowadays a critical challenge is experienced by the Department of Pediatric Dentistry and Dental Public Health to determine dental needs utilization changes, in the general population, aroused by the COVID-19 pandemic. Also, temporary closure of the Students Medical Insurance Coverage Units by the general authorities increased the current responsibilities offered by the Out-Patients' clinic. Emergency dental care decided by the department board, as minimally invasively as possible, included dental pain due to caries, acute gingival conditions, and dental trauma (pain, avulsion, luxation).

The present results showed a reduction of urgent dental care utilization services by children visiting the Out-Patients' clinic for the first time by the date of declaration of the Egyptian partial curfew. This was in accordance with Guo et al., $2020^{9}$ who stated that the number of patients visited the dental urgency at the beginning of the COVID-19 pandemic in Beijing, China had been reduced (38\% fewer patients).

The current results strongly suggest that COVID-19 significantly affects parental attitude towards the utilization of emergency dental care. Following the Egyptian authorities' recommendations, people became reluctant to go to the public places outside, and their willingness to visit the dental institutions was reduced. Moreover, more parents were expected to seek emergency dental care only when it was needed instead, consolation of most dental problems was achieved through phone communication services offered by many private dental care practices ${ }^{12}$.

Meanwhile, among the children attending the Out-Patients' clinic for the first visit for urgent care, there were actual emergency complaints and nonemergency complaints. This was the same situation in the study held by Guo et al., $2020{ }^{9}$ where $18.3 \%$ of patients with non-emergency complaints sought urgent dental care units before the COVID-19 pandemic ${ }^{13}$ This is because public dental institutions are convenient, accessible, and affordable for all patients. Meanwhile, the dental fees of private dental services are far beyond the limits of parents with low and moderate economic levels.

There was no significant difference between girls and boys among both groups. This was similar to what was previously observed by Guo et al., $2020{ }^{9}$ However this was opposite to the results of Tramini et al., $2019^{13}$ who observed that females sought dental emergency care significantly less often than males, where females fear acute viral respiratory tract infection transimisson more readily than males ${ }^{14}$ And this was not the condition in our research because the guardian is the decision-maker for seeking dental care for the child. 
Most of the children were living in Cairo and Giza governorates, where both governorates possess a high population occupational density and the location of the Faculty of the Dentistry Hospital is considered a nearby destination to both governorates offering ease of transportation ${ }^{15}$

The age group of the study population was from birth to 15 years of age. The study results showed that the mean age of children studied after curfew was $7.61 \pm 2.33$ and before the curfew was $6.70 \pm 2.42$. This may be due to high caries prevalence in this age group, and the start of shedding of primary incisors, and eruption of permanent incisor and first permanent molars which is usually accompanied by gingival inflammation and swelling ${ }^{16}$

Most of the cases in both groups sought actual emergency treatment due to dental caries, acute gingival conditions, and dental trauma with the nonsignificant difference between the two groups. This may be due to that the etiological factors of dental caries (chronic disease taking a considerable time to develop and strongly related to dietary habits) and acute gingival condition (acute infections related to dental caries and oral lesions) are supposed not to be dramatically changed before and after the lockdown.

Based on the fact that social and conventional activities were limited by the general authorities, the incidence of dental trauma was supposed to decrease similar to what was reported by Guo et al, $2020{ }^{9}$ (10.5\% vs. 14.2\%) due to reduced outdoor activities, however this was not the scenario; there was a non-significant difference between the percentages of dental trauma among the two groups. This may be attributed to the fact that children seeking emergency dental care at public dental institutions do not follow strictly the general authorities' recommendations by limiting outdoor activity and were still playing in the suburb's streets.

Meanwhile, most of the cases of non-emergency dental needs recorded in the current research were complaints other than esthetic and restorative needs (preventive measures, chronic gingival condition, etc. ${ }^{17-19}$

\section{CONCLUSIONS}

The results of the current work suggest that the COVID-19 pandemic affected the number of children seeking urgent dental care, where the number of emergency dental visitors reduced to about half, even fearing the COVID-19, children seek emergency dental services when suffering from severe toothache, acute gingival conditions, and dental trauma.

The proportion of emergency dental complaints (dental caries, acute gingival conditions and dental trauma) and non-emergency complaints are somehow comparable before and after partial curfew declaration.

Unexpectedly, incidence of traumatic dental injuries was not influenced.

The utilization of emergency dental care is influenced by the population occupational density, accessibility of dental health care, and ease of transportation.

\section{REFERENCES}

1. Li Q, Guan X, Wu P, et al. Early Transmission dynamics in Wuhan, China, of novel coronavirus infected pneumonia. N Engl J Med 2020; 382:1199-1207.

2. Gorbalenya AE. Severe acute respiratory syndrome-related coronavirus e the species and its viruses, a statement of the coronavirus study group. BioRxiv, 2020.

3. Zhu N, Zhang D, Wang W, et al. A novel coronavirus from patients with pneumonia in China, 2019. N Engl J Med 2020; 382: 727e33.

4. WHO. Statement on the second meeting of the International Health Regulations (2005) Emergency Committee regarding the outbreak of novel coronavirus (2019-nCoV). 2020, https://www.who. Retrieved on: June 2020.

5. MOHP. Protocol of MOHP may 2020 for Corona virus diagnosis and treatment. https//mohp.gov.eg. Retrieved on: June 2020

6. Harrel SK, Molinari J. Aerosols and splatter in dentistry: a brief review of the literature and infection control implications. J Am Dent Assoc 2004;135: 429e37. 
7. Gomes PM, Leite ICG, Veperino RG (2018) Integrality in Oral Health: Analysis of Referral from a Primary Care Unit to a Brazilian Dental Specialties Center. J Dent Health Oral Disord Ther 9(1): 00326. DOI: 10.15406/jdhodt.2018.09.00326

8. Curi DSC, Figueiredo ACL, Jamelli SR. Factors associated with the utilization of dental health services by the pediatric population: an integrative review. Ciênc \& saúde coletiva, 23, 2018: 1561-1576

9. Guo H, Zhou Y, Liu X, Tan J. The impact of the COVID-19 pandemic on the utilization of emergency dental services. Journal of Dental Sciences. 1-4. https://doi.org/10.1016/j. jds.2020.02.002. Retrieved on: June 2020.

10. CDC, 2020. Guidance for Dental Settings. Interim Infection Prevention and Control Guidance for Dental Settings During the COVID-19 Response. https://www.cdc.gov/ coronavirus/2019-ncov/hcp/dental-settings.html. Retrieved on: June 2020.

11. ADA, 2020. Emergency and non-emergency guidance. https://www.ada.org/en/publications/ada-news/2020-archive/march/ada-develops-guidance-on-dental-emergency-nonemergency-care . Retrieved on: June 2020.

12. Shqair AQ, Gomes GB, Oliveira A, et al. Dental emergencies in a university pediatric dentistry clinic: a retrospective study. Braz Oral Res 2012; 26:50e6.
13. Tramini P, Al Qadi Nassar B, Valcarcel J, Gibert P. Factors associated with the use of emergency dental care facilities in a French public hospital. Spec Care Dent 2010; 30:66e71.

14. Ashok N, Rodrigues JC, Azouni K, et al. Knowledge and apprehension of dental patients about MERS-A questionnaire survey. J Clin Diagn Res 2016;10: ZC58e62.

15. McKernan S C, Reynolds J C, Ingleshwar A, Pooley M, Kuthy R A, Damiano P C. Transportation Barriers and Use of Dental Services among Medicaid-Insured Adults. JDR Clinical \& Translational Research 2018. 3(1):101-108.

16. Babaei1 A, Pakdaman A, Hessari H and Shamshiri a R. Oral health of 6-7-year-old children according to the Caries Assessment Spectrum and Treatment (CAST) index. BMC Oral Health 2019. https://doi.org/10.1186/s12903-018-0709

17. Youssefi M A and Afrough S. Prevalence and Associated Factors of Dental Caries in Primary Schoolchildren: An Iranian Setting 2020. https://doi.org/10.1155/2020/8731486. Retrieved on: June 2020.

18. Zou J, Meng M, Law C S, Rao Y and Zhou X. Common dental diseases in children and malocclusion. International Journal of Oral Science (2018) $10: 7$

19. Si Y, Tai B, Hu D, et al. Oral health status of Chinese residents and suggestions for prevention and treatment strategies. Glob Health J 2019; 3:50e4. 